\title{
PESQUISA-AÇÃO E FORMAÇÃO DE EDUCADORES NA/DA EDUCAÇÃO NÃO-FORMAL O REGISTRO DA PRÁTICA COMO ELEMENTO DE REFLEXÃO*
}

\author{
ACTION RESEARCH AND TRAINING EDUCATORS IN / NON-FORMAL EDUCATION: \\ THE REGISTRATION OF PRACTICE AS AN ELEMENT OF REFLECTION
}

Renata Sieiro Fernandes ${ }^{* *}$

Doutora em Educação - Unicamp | Brasil E-mail: rsieirof@hotmail.com

REVISTA PEDAGÓGICA

Revista do Programa de Pós-graduação em Educação da Unochapecó | ISSN 1984-1566 Universidade Comunitária da Região de Chapecó | Chapecó-SC, Brasil Como referenciar este artigo: FERNANDES, R. S. Pesquisa-ação e formação de educadores na/da Educação não-formal: o registro da prática como elemento de reflexão. Revista Pedagógica, Chapecó, v.15, n.31, p. 73-85, jul./dez. 2013.

RESUMO: Este artigo apresenta um recorte da pesquisa-ação realizada no campo da educação não-formal, focalizando especialmente a discussão do registro da prática educativa, como elemento de reflexão sobre o saber docente. Essa discussão teve lugar dentro de curso de formação para educadores e coordenadores pedagógicos, como recurso para se repensar problemáticas do cotidiano e para se reorientar possibilidades de superação e melhoria. O interesse particular de cada uma das duas instituições envolvidas foi investir na formação contínua de seus educadores e rever suas opções teórico-prática-metodológica, orientadas por princípios filosófico-político de formação de sujeitos que melhor se adequassem ao campo da educação não-formal e ao papel institucional de organizações na sociedade atual encaminhados pelos educadores e coordenadores pedagógicos.

PALAVRAS-CHAVE: Educação não formal. Formação de educadores. Registros docentes.
ABSTRACT: This paper presents a part of the action research conducted in the field of non-formal education, especially focusing on the discussion of the registration of educational practice as an element of reflection of teaching knowledge. This discussion took place through a training course for educators and coordinators as a way to rethink issues of daily life and also to reorient possibilities of overcoming and improving. The interest of each institution involved has been investing in the continuing education of educators and review your options theoretical, practical and methodological. The study focuses on the philosophical principles and political training of subjects aimed at better matching to the field of non-formal education and the institutional role of organizations in society today.

KEYWORDS: Non-formal education. Continuing education. Teacher records. 


\begin{abstract}
* Artigo reelaborado a partir de comunicação oral apresentada no $10^{\circ}$ Encontro de Pesquisa em Educação da Região Sudeste, Universidade Federal do Rio de Janeiro (UFRJ), em julho 2011.

** Pedagoga, mestre e doutora em Educação pela Universidade de Campinas (UNICAMP). Docente do Programa de Mestrado em Educação Sociocomunitária, do Centro Universitário Salesiano de São Paulo (UNISAL). E-mail: rsieirof@hotmail.com
\end{abstract}

1 A pesquisa intitula-se "Educação em diferentes contextos e os espaços da cidade" e foi desenvolvida nos anos de 2008-2010, na Faculdade de Educação, junto ao Departamento de Ciências Sociais na Educação (DECISE), da Universidade de Campinas (UNICAMP), dentro do Programa de Apoio a Projetos Institucionais com a Participação de Recém-Doutores (PRODOC). Financiamento: Capes.

\section{INTRODUÇÃO}

Este texto apresenta um recorte da pesquisa-ação ${ }^{1}$ realizada no campo da educação não-formal, focalizando especialmente a discussão do registro da prática educativa como elemento de reflexão sobre o saber docente, dentro de um curso de formação para educadores e coordenadores pedagógicos como recurso para se repensar problemáticas do cotidiano e para se reorientar possibilidades de superação e melhoria.

Ao longo dos dois anos (2008-2010) de desenvolvimento da pesquisa-ação, os campos de investigação e ação centraram-se em dois espaços de educação não-formal, localizados em regiões periféricas de Campinas, em São Paulo: o Projeto Gente Nova (Progen), localizado na Vila Castelo Branco, e o Centro Promocional Tia Ileide (CPTI), localizado no Nova Aparecida.

O interesse particular de cada uma dessas instituições foi investir na formação contínua de seus educadores e rever suas opções teórico-prática-metodológica, orientadas por princípios filosófico-político de formação de sujeitos que melhor se adequassem ao campo da educação não-formal e ao papel institucional de organizações na sociedade atual encaminhados pelos educadores e coordenadores pedagógicos.

Uma das estratégias para se alcançar isso foi a elaboração e o desenvolvimento de um curso de formação, em cada instituição, para todos os educadores e coordenadores que ocorreu ao longo do primeiro e segundo ano de pesquisa (2008 e 2009), em cada espaço institucional. Após esse período, no ano seguinte (2010) o foco deu-se em reuniões e encontros presenciais de orientação com coordenadores e educadores, individualmente ou em grupo, ou a distância, via e-mail.

O formato e conteúdo dos cursos de formação foram criados tomando-se por base os interesses e demandas particulares de cada instituição e somando a assuntos que a pesquisadora indicou a fim de compor um "desenho" de curso negociado entre ambos os lados.

No meio do percurso, teve-se a oportunidade de se valer da Reserva Técnica da Bolsa para a construção e utilização de um site, especialmente construído para esta pesquisa, como instrumento de publicização das práticas e reflexões, como meio de registro e sistematização dos trabalhos, como espaço de conversas e trocas virtuais, a distância, entre educadores e coordenadores/as de ambas as instituições, visando aproximar as realidades e experiências, compartilhar dúvidas, soluções e sugestões. E que serve para dar continuidade ao trabalho iniciado mesmo após a finalização da pesquisa - que ocorreu em novembro de 2010. 


\section{AS INSTITUIÇÕES FOCALIZADAS}

As duas instituições de educação não-formal focalizadas localizam-se na periferia de Campinas (SP). Trabalham com públicos semelhantes, especialmente com crianças e jovens, mas atendem também adultos, muitos deles, pais ou responsáveis familiares dos frequentadores.

Desenvolvem trabalho de educação não-formal, na medida em que não dependem de legislações ou regulamentações do Ministério da Educação (MEC), conforme define Trilla (1996). Para esse autor, os conceitos são definidos de forma pontual, e o que difere o formal do não formal é sua relação direta e dependente de um órgão externo, superior, ligado ao Estado que, no caso brasileiro, identifica-se com o MEC. Para ele,

[...] a educação formal é aquela que tem uma forma determinada por uma legislação nacional, ou seja, que tem critérios específicos para acontecer e que segue o que é estipulado pelo Estado - a educação escolar, hoje compreendida pela educação infantil, ensino fundamental, médio e universitário. A educação não formal é: a) toda aquela que é mediada pela relação de ensino-aprendizagem, tem forma, assume e desenvolve metodologias com procedimentos e ações diferenciadas das adotadas nos sistemas formais, e b) estruturalmente, não tem uma legislação nacional que a regula e incide sobre ela. (Trilla, 1996, grifo nosso).

Ou seja, uma série de programas, propostas, projetos que realizam ações e interferências, que são perpassados pela relação educacional, mas que se organizam e se estruturam com inúmeras diferenças - um leque bastante amplo de possibilidades contempla a educação não formal.

Baseando-se em Trilla e Palhares (2009), considera-se que uma série de situações que envolvem valores educativos, embora sem ter necessariamente planejamento para isso, acontecem-nos diariamente pela via das mídias e especialmente pela via das relações e interações sociais e pessoais e familiares.

Rogers (2005) usa a imagem do iceberg para ilustrar que o que fica submerso e nem sempre visível é justamente a parte que dá base e sustentação para o que fica na superfície e, para tanto, localiza a educação informal como sendo essa parte ampla e abrangente que sustenta a educação formal e a educação não formal, isto é, a educação informal tanto sustenta quanto é constituinte dos outros modos e especificidades educacionais.

Essas definições são apenas didáticas e servem para nos mostrar que tudo se relaciona e que embora possa se fazer um recorte específico em algum tipo de conceito, necessariamente os demais e relacionados a esse estão presentes na discussão. 
Ambas as instituições da pesquisa são organizações da sociedade civil e estabelecem convênios, recebem verbas de órgãos públicos estaduais, municipais e federais, bem como doações e recursos de fontes privadas. Estão ligadas à Secretaria de Assistência Social do município e estão filiadas à Federação das Entidades de Assistência Social (FEAC), atuando prioritariamente na área da proteção às crianças de famílias de baixa renda, o que se traduz no termo "ação social" (Martins, 2005).

As duas instituições têm origens diferenciadas, sendo o Progen de origem religiosa, com freiras da ordem salesiana de Dom Bosco - hoje não mais - e o CPTI originado de movimento social, especialmente por iniciativa de uma mulher chamada Ileide.

Tanto o Progen quanto o CPTI atuam em mais de um bairro, contando com sede e núcleos externos. A primeira tem sede na Vila Castelo Branco e núcleo externo no bairro do Satélite Íris. A segunda tem sede na Vila Mendonça e núcleo externo no bairro da Vila Francisco, bairros de ocupação, no distrito de Nova Aparecida.

\section{A PESQUISA-AÇÃO COMO METODOLOGIA}

Esta pesquisa, de cunho qualitativo, investigativo, como já foi relatado, primeiramente elaborada como sendo baseada na observação de campo participante, reorientou-se para uma pesquisa-ação, com focos e interesses institucionais de intervenção, visando aperfeiçoamento das ações educativas pensadas e realizadas em seus espaços, envolvendo coordenadores, educadores e público frequentador infantil e juvenil, com trabalho de campo e com referenciais da história oral nos momentos de entrevista, de organização e seleção dos materiais, tratamento dos dados a partir de categorias extraídas do material reunido e possíveis interpretações.

O intuito da pesquisa-ação é a melhoria de processos, relações ou hábitos, implicando mudanças comportamentais e/ou estruturais, no caso de envolver instituições e equipe de profissionais juntamente com o público que assiste (Gatti, 2008).

Para Gatti (2008), citando Kurt Lewin, o processo que tal metodologia de pesquisa envolve é composto por quatro atividades: o planejamento visando à melhoria ou mudança de uma determinada situação; a atuação para implementar a mudança intencionada; o acompanhamento e a descrição dos efeitos da ação e a análise e interpretação de todo o processo.

A busca pela mudança foi uma necessidade sentida e intencional por ambas as instituições envolvidas na pesquisa e a busca pela pesquisadora se deu em momento concomitante, no sentido de ajudar a compreender a realidade e de buscar readequá-la melhor ao campo da educação não-formal. 
Nesse sentido, segundo Barbier (2004, p. 43),

[...] a mudança visada não é imposta de fora pelos pesquisadores. Resulta de uma atividade de pesquisa na qual os atores se debruçam sobre eles mesmos. Se o processo é induzido pelos pesquisadores, em função de modalidades que eles propõem, a pesquisa é efetuada pelos atores em situação e sobre a situação destes. A ação parece prioritária nesse tipo de pesquisa, mas as consequências da ação permitem aos pesquisadores explorá-las com fins de pesquisa mais acadêmica.

A necessidade de se fazer uma pesquisa-ação surge de um problema ou problemática que nasce em um contexto preciso e para um determinado grupo, não sendo fruto de uma provocação do pesquisador. A ele cabe constatar a problemática, focá-la - identificando o que prevalece, o que bloqueia, o que falta - e auxiliar o grupo a tomar consciência dela, fornecendo retornos constantes e avaliações interpretativas referenciadas teoricamente - no sentido de o grupo assumir responsabilidades e fornecer instrumentos que colaborem para/com a mudança (Barbier, 2004, p. 54).

Para tanto, é preciso que ocorra um contrato entre todos os envolvidos, mas um contrato aberto, como propõe Morin (apud Barbier, 2004, p. 120):

[...] aberto em todas as suas dimensões, tanto na problemática, na análise das necessidades, na definição dos problemas, nos questionamentos, quanto na metodologia, incluindo a construção de instrumentos de coleta de dados e a revisão da informação concernente aos significados das ações.

Como coloca Garrido (apud Gatti, 2008), assume-se aqui a perspectiva crítico-colaborativa, buscando construir sentidos, significados e interpretações de modo compartilhado, que vão se construindo gradativamente, não sem retrocessos, impasses e conflitos, mas também com avanços e empenho, por meio de envolvimento e interações próximos entre pesquisador e os sujeitos pesquisados: a possibilidade e necessidade ética da articulação emancipatória entre pesquisador e sujeitos pesquisados, conferindo à atividade científica um compromisso com a fertilização de teorias e ações que (subsidiem) a práxis dos professores, no sentido da transformação das condições de ensino e de aprendizagem, por meio da transformação de sentido que passariam a conferir às práticas institucionais.

Conforme Thiollent (1982), toda pesquisa-ação é uma forma de pesquisa participante e está preocupada com o agir sobre determinada situação. O pesquisador está junto com os demais envolvidos na pesquisa embora não participe cotidianamente de seu campo de ação. A participação dos pesquisados é ponto fundamental para a realização da pesquisa, pois eles dão as demandas, desenvolvem 
ações reorientadas e fornecem os materiais de retorno que servem de análise e interpretação para a resolução de alguma problemática coletiva sob a forma de ação concreta, bem como para a conscientização, o conhecimento, a ampliação do debate dos grupos envolvidos (Thiollent, 1994).

Para poder se ater mais detidamente no trabalho de investigação, foram focadas duas instituições não formais que atenderam ao interesse de trabalhar coletivamente e em parceria (entre si e com os espaços da cidade) na construção de pedagogias diferenciadas de ensino-aprendizagem que envolvam práticas culturais e artísticas que correspondam aos interesses e características dos grupos com os quais se envolvem diretamente.

Todo o processo de investigação e pesquisa contou com registros do cotidiano em diários de campo de forma escrita, imagética, sonora etc, conforme melhor se adequaram aos dados coletados e às situações de coleta empírica.

Fez parte da metodologia desta pesquisa oferecer cursos de formação para os educadores e coordenadores pedagógicos das duas instituições focalizadas, centrando-se no histórico e conceituação da educação não-formal e na reformulação de metodologias de trabalho pedágogico e registros reflexivos, para que pudessem se conscientizar e desenvolver ações mais voltadas para o campo e o público com que lidam.

Paralelamente a isso, buscar aproximar as duas instituições e os educadores e coordenadores - física e virtualmente -, de modo que possam trocar experiências e referenciais e, assim, construir e reforçar laços profissionais que auxiliem o processo de aprimoramento do ato educativo. Com isso, provoca-se o movimento de fazer a "periferia falar com a periferia". Essa tentativa aconteceu durante a pesquisa e a perspectiva é que continue acontecendo por iniciativa própria das instituições, já que foi uma estratégia aprovada por educadores e coordenadores pedagógicos.

Para tanto, encontros presenciais aconteceram - em janeiro e em agosto de 2009 e em outubro de 2010 -, uma vez em cada uma das instituições e os encontros virtuais aconteceram através de um site que serve como "janela" para os educadores se comunicarem, trocarem experiências e fazerem registros de suas ações, juntamente com os educandos.

Dentro dos encontros de trabalho, destacamos os encontros que aconteceram com ambas as equipes para ajudar na elaboração e construção do site pela empresa contratada e, posteriormente, para apresentação da versão final, no $1^{\circ}$ semestre do ano de 2010.

Outro encontro em cada uma das instituições juntando educadores, coordenadores, pesquisadora e construtores do site aconteceu em março de 2010 para apresentação 
e manuseio do mesmo, como uma "oficina de trabalho" em que os educadores iniciaram o preenchimento do mesmo.

A necessidade do registro e o processo reflexivo

O foco no registro na formação dos educadores e coordenadores se justifica em função de os registros serem os meios pelos quais a reflexão acontece. É por meio da reflexão que os profissionais se apropriam e se reconhecem nas suas práticas.

\section{Para Madalena Freire (1996),}

Ficamos para os outros através de nossos registros. O registro escrito não é o único ou o mais importante. Quando escrevemos desenvolvemos nossa capacidade reflexiva sobre o que sabemos e o que ainda não dominamos. O ato de escrever nos obriga a formular perguntas, levantamento de hipóteses, aonde vamos aprendendo mais e mais, tanto a formulá-las quanto a respondê-las. Essa capacidade tão vital de perguntar, que nos impulsiona à vitalidade de pensar, pesquisar, aprender, todo educador tem que educar. Assim o registrar de sua reflexão cotidiana significa abrir-se para seu processo de aprendizagem.

Registrar é inscrever algo vivido ou projetado - como rascunho, esboço -, em algum suporte físico, tangível ou intangível. Sendo assim, é preciso estar de prontidão para a percepção, a apreensão, a captura, assim como acontece com o artista. Para tanto, dois movimentos iniciais são imprescindíveis:

- A experiência do cotidiano, que é aquilo que nos passa, o que se perde e o que fica, com o que ela traz de iminência, de acaso, de imprevisto, de rupturas, do que foi possível;

- O olhar, a escuta e demais sentidos atentos para evocarem o tempo do estabelecimento das relações com as coisas ao redor. A ação de inscrever, de registrar, é a forma possível de se apropriar da experiência vivida, da história e da memória.

Além dessas intenções, outras se abrem ou aparecem nesse movimento: a deflagração de algo novo, a instauração, a provocação, o rompimento, a ampliação ou alargamento de limites.

Nesse sentido, são necessárias algumas ferramentas ou posturas para esse processo de imersão e certo encantamento: dispor de tempo, ter presença, disciplina, concentração, método, pesquisas, consultas, trocas, escolhas, decisões, prontidão, tateios e erros, divagações, criatividade, imaginação.

Entretanto, registrar não implica em produzir algo reflexivo. A reflexão é uma ação posterior, em que as habilidades do pensar, como: estabelecer agrupamentos, 
categorizações, classificações, ordenações, relações, generalizações, extrapolações, comparações, sínteses, composições, sobreposições, seleções, edições, análises, esforços de interpretação.

Alguns cuidados no seu preparo e elaboração precisam ser tomados para se pensar quando registrar, como, por parte de quem, os conteúdos (mais de um tipo de registro para determinados pontos e compor com diferentes registros) eleitos etc., de forma que possam "falar" por si sós: a) O registro trata do que?; b) Qual o suporte utilizado?; c) Que linguagens utiliza? d) Para quem fala?; e) O que o registro mostra o que tem de conteúdo, de estudo e pesquisa?; f) Para que serve ou como é utilizado?; g) É aberto ou fechado/concluído? É privado ou público?; h) É reflexivo ou não?; i) Em que momentos foram feitos?

Além de servirem como memória do processo, os registros são importantes e essenciais instrumentos orientadores tanto para o processo de avaliação quanto de (re)planejamento do trabalho e de reflexão para o educador que, assim, se apropria de sua prática, de seus fazeres e de seus saberes. Ao lado disso, constitui-se como acervo, memória e história das instituições, daí a preocupação de se atentar para esse elemento importante do processo da prática educativa e docente.

\section{O SITE COMO INSTRUMENTO DE PESQUISA E FONTE DE DADOS}

A intenção inicial do site era que ele servisse como um diário de campo da pesquisa e que também abrisse links para espaços virtuais a serem preenchidos pelo Progen e pelo CPTI. Dessa forma, o site seria um instrumento processual de registro e divulgação da pesquisa para amplos públicos, como também, um material de análise de pesquisa.

As perguntas que motivaram a coleta de dados para análise foram: a) ele é/será usado como material de registro e instrumento de comunicação e reflexão? Como?; b) educadores/as têm dificuldade com a linguagem da informática?; c) O que é/será publicado?; d) os educandos têm facilidade com a linguagem?; e) Facilita um instrumental com linguagem multimídia?; f) E o tempo para alimentá-lo é conseguido como?; g) como habilitar os/as educadores/ as para fazerem isso?

Os materiais que serviram para alimentar a ideia do site foi o blog do próprio CPTI, feito pelo grupo de seis educadores que vem trabalhando junto no núcleo da Vila Mendonça tendo como ponto de partida a construção de uma casa na árvore e os blogs dos educadores do Centro Educacional Unificado (CEU), em São Paulo, que são exigidos como fonte de registro do cotidiano e do processo das práticas educativas dos educadores desse espaço escolar formal. Serviu como fonte inspiradora por se colocar como 
2 Ver blogs da educadora Aira, do CEU (SP), disponível em: <www.airaejuliananoceu. blogspot.com > (dança e plásticas), <www. airaeregisnoceu.blogspot.com $>$ (teatro e plásticas), <www.airaejanetenoceu.blogspot.com> (teatro e plásticas). Ver também da educadora Juliana, do CEU (SP), disponível em: $<$ http://julianaelucianonoceu.blogspot.com> (música). um meio multimídia e focado no registro da prática de trabalho docente, já que não encontramos muitos materiais desse tipo e com esse uso para serem pesquisados e serem utilizados como inspiração para a construção do site desta pesquisa $^{2}$.

A equipe responsável pela construção do site, da empresa Preface, fez reuniões iniciais com a pesquisadora para saber as diretrizes com que deveriam começar a planejar a estrutura e os conteúdos do site. Posteriormente, fez reuniões conjuntas com a pesquisadora e com as coordenadoras do Progen e CPTI para saber como pensavam em se aproveitar do site para propor aos seus educadores e, por fim, fez reuniões conjuntas comigo, com as coordenadoras e os/as educadores/as de ambas as instituições para que fossem fornecidas demandas para o uso no cotidiano, e quando da entrega do site, totalizando 6 (seis) encontros.

A partir desses encontros a equipe de construção do site elaborou versões preliminares de estrutura e conteúdo e foi apresentando aos diferentes grupos para que fossem feitos ajustes.

Dessa forma, a ideia inicial que tínhamos do site servir como um diário de campo da pesquisa mudou para a ideia de ser um caderno de registros de ambas as instituições, com características visuais específicas para cada uma, de forma que fossem, também, "janelas" destravadas, "sem tramelas", por onde pudessem se ver e serem vistos e trocarem comentários, projetos, consultas, dicas etc. As entradas da pesquisadora se dão pela via de comentários e de posts pontuais, devidamente identificados.

Sendo assim, o site serve, inclusive, para uma função incluída na pesquisa, a de material de análise de uso por parte dos educadores no sentido de servir como incentivo ao registro da prática - foco de interesse das instituições dos educadores, bem como de fazer a "periferia falar com a periferia" e de ser conhecido pelo mundo - sem controle disso - e de deixar o mundo entrar - postar comentários, ver, compartilhar etc.

O site recebeu o nome de "Sem Tramelas" depois de passar por um levantamento inicial feito com os educadores de ambas as instituições. Ele foi escolhido justamente por transmitir a ideia da pesquisa que é as duas instituições se verem e serem vistas, podendo conversar entre si tendo o site como um mediador virtual, abrindo-se como janelas sem trancas.

Uma apresentação mais detalhada do site aconteceu quando da entrega da versão final do mesmo e após o trabalho de "preenchimento" da mídia com o grupo de educadores das duas instituições.

Como exemplo de sua estrutura, a primeira tela do site mostra a página de documentos geral, e também é a página inicial do site, mostrando uma visão geral de todos os 
documentos, de ambas as entidades. A segunda tela mostra a página de um projeto, com todos os seus documentos. A terceira página "desdobrada" de um documento de um projeto, com texto, fotos, comentários etc. A quarta página mostra o perfil resumido dos participantes do projeto.

Após a hospedagem do site no endereço virtual, os educadores, de seus locais de trabalho, começaram a postar materiais e conteúdos de seus trabalhos. Entretanto, apenas dois educadores, do CPTI, o fizeram efetivamente até o momento de finalização da pesquisa, em 2010. Ambos contaram um pouco do que estava acontecendo em suas oficinas de trabalho: uma que trata da construção de personagens de heróis e heroínas - usando, inclusive, um programa da internet - e outra que enfatiza o corpo. Postaram registros pontuais, de forma escrita, em vídeo, fotos - com trilha sonora de fundo - e desenhos, mostrando o potencial desse instrumento.

A partir dessa constatação do uso ainda tímido e pensando nos educadores recém-chegados em ambas as instituições, e na coordenadora pedagógica recém-contratada no Progen, os coordenadores se moveram para programar um encontro interinstituições, que aconteceu nas dependências do CPTI, envolvendo educadores e equipe pedagógica, para que ficassem a par do site.

Com a finalização da pesquisa-ação, o site passa a ser meu foco como pesquisadora, ou seja, continuarei dando contribuições necessárias e apoio às instituições para que o uso se efetive de fato, bem como questionar e problematizar sobre seu uso.

\section{OUTROS REGISTROS DO COTIDIANO}

No Progen, os educadores passaram a fazer registros de seus trabalhos mais tardiamente do que no CPTI. Começaram, a compor seus registros em papel sulfite encadernado - forma escolhida e adotada pelas coordenadoras, tomando como parâmetro os registros sob a denominação de Livro da Vida, utilizados na Pedagogia Freinet.

Alguns exemplos de registros feitos pelos educadores e educandos valem-se por meio da escrita, colagem e fotos. Alguns são tímidos e outros mais ousados e coloridos. Há um registro em processo de construção por parte de uma educadora que, tendo selecionado e guardado registros fotográficos, ainda não havia conseguido organizá-los sob uma forma a seu contento, mostrando a desordem inicial, mas em processo de ordenação - princípio de organização e sistematização.

\section{CONSIDERAÇÕES GERAIS}

O projeto de pesquisa nos anos de 2008 a 2010, nem sempre se desenvolveu a contento, em virtude dos percalços e das descontinuidades próprias da vida cotidiana, especialmente se levarmos em conta o período extenso que 
durou. Entretanto, é possível perceber deslocamentos por parte dos educadores, coordenadores pedagógicos das instituições envolvidas, o Progen e o CPTI, assim como, da pesquisadora. A sensação que fica é que empreender uma pesquisa-ação no universo das ONG's, frente à realidade em que estão envolvidas, exige muito esforço de ambos os lados e, muitas vezes, o que se inicia como uma demanda urgente, ao longo do tempo, passa a ser secundária em razão de outras urgências burocráticas, - como captação de recursos, escritas de projetos, relatórios de prestação de contas -, de reestruturações - trocas de função, alta rotatividade de funcionários - e de limitações dos próprios educadores - falta de tempo, muitas tarefas cotidianas se sobrepondo ao pedagógico, reflexão e ação mais lentas quando comparadas as expectativas da instituição e da pesquisa.

Houve muitas frustrações ao longo da pesquisa, muitas reorientações - que é próprio de uma pesquisa deste tipo - e alguns pontos foram deixados de lado ou preteridos. Também houve satisfações por perceber mudanças nas práticas pedagógicas dos educadores e entusiasmo verbalizado por parte deles ao perceberem e incorporarem novas possibilidades em seus trabalhos.

Um fator importante é que em uma pesquisa-ação, ambos os lados precisam estar bem envolvidos e comprometidos com o desenrolar da pesquisa, estando atentos para as devolutivas e tentando implementá-las e garantir sua manutenção por meio de cobranças e avaliações constantes. Nisso entra, especialmente, o papel dos coordenadores pedagógicos, que nem sempre conseguiram dar conta por serem muito atarefados no dia a dia, a pesquisa levar a eles mais atribuições e também pelo ritmo de mudança dos educadores não ser homogêneo e necessitar de "mais tempo", incentivo, acompanhamento diferencialmente.

Foram produzidos dados importantes para análise acerca do trabalho pedagógico desenvolvido pelos educadores no campo da educação não-formal. Ao lado disso, os retornos constantes proporcionados pela metodologia empregada serviram como referência para reavalições e rearranjos tanto na estrutura como no fazer prático e reflexivo do trabalho educativo, contribuindo para a formação em serviço e continuada de educadores e educandos, que eram objetivos da pesquisa-ação.

O ritmo de mudanças foi/é heterogêneo nas duas instituições e, por vezes, muito moroso. Os educadores e coordenadores pedagógicos têm potenciais e disposições diferenciados.

Uma característica do universo da educação não-formal, como o lugar de trabalho, e que foi um agravante para descontinuidades, foi a alta rotatividade de educadores e coordenadores, no período de 2008 a 2010. Isso atrapalhou a manutenção de uma regularidade no curso de formação 
em ambas as instituições e interferiu no trabalho, pois os que chegam tomam parte das discussões e das proposições no meio do caminho e é difícil recuperar o já passado.

O dia a dia dos educadores, mais no Progen do que no CPTI, costuma ser muito corrido e, praticamente, o tempo em que estão na instituição é dedicado diretamente aos educandos. Eles ressentem por não haver pausas e momentos de distração. É preciso que as instituições busquem garantir e manter espaço para os educadores estarem entre si, prepararem materiais, fazerem registros sob diferentes suportes e, inclusive, no site e no próprio espaço da instituição, pois nem todos o fazem em casa, como uma forma de investir na qualidade do trabalho deles e na possibilidade de fazerem pesquisas de materiais e de produzirem registros reflexivos de seus trabalhos.

Essa correria do cotidiano - que não é exclusiva dos educadores, também acomete os coordenadores em virtude de receberem muitas demandas e realizarem muitas tarefas - isso quase impede reflexão. Fica-se na prática e impede-se o distanciamento necessário para o pensar, refletir.

A realidade da educação não-formal, especialmente no caso de ONG's, faz com que muito do tempo dos coordenadores e demais funcionários seja dispensado visando buscar editais de fomento, escrever projetos para serem financiados, fazer relatórios de prestação de contas, implicando um não "mergulho" nos fazeres pedagógicos. Em virtude disso, as demandas iniciais, que é o fazer pedagógico, em pouco tempo passam para o segundo plano - mas continuam a ser essenciais -, e o dia a dia é quase como ter que "apagar incêndios". Então, muitas tarefas previamente assumidas ou elaboradas intencionalmente não foram possíveis de acontecer.

Sobre os registros feitos no dia a dia com os educandos e educadores, no CPTI funcionaram bem e ainda estão em andamento. No Progen, alguns educadores os incluíram e outros ainda não sabem como incorporará-lo no planejamento e no horário de trabalho. Também há que se considerar o fato de que nem todos os educadores têm facilidade com a escrita.

Quanto ao site, ao finalizar esta pesquisa-ação, o que se pode percebe é que o uso ainda é restrito e incipiente, mas aos poucos os coordenadores vão estimulando os educadores para que façam uso desse instrumental que servirá tanto a eles e as instituições como lugar de registro e fomento de suas ações e ideias e projetos quanto para futuras pesquisas que se preocupem com esse aspecto do cotidiano dos educadores em suas práticas educativas, que é o registro pontual, o registro reflexivo e as trocas de saberes entre educadores e instituições de educação não-formal. 


\section{REFERÊNCIAS}

BARBIER, René. A pesquisa-ação. Brasília: Líber Livro, 2004.

FREIRE, Madalena. Observação, registro e reflexão: instrumentos metodológicos 1. São Paulo: Espaço Pedagógico, 1996.

GATTI, Bernadete A. Pesquisa em ação: produção de conhecimentos e produção de sentidos como desafio. São Paulo, 2008. Mimeografado.

MARTINS, José P. S. FEAC: biografia de um pacto social. Campinas SP: Átomo, 2005.

PALHARES, José Augusto. Reflexões sobre o não-escolar na escola e para além dela.

Revista Portuguesa de Educação, Braga, PT, v. 22, n. 2, p. 53-84, 2009.

ROGERS, Alan. Non-formal education: flexible schooling or participatory education? Nottingham: Universities of Nottingham \& East Anglia, 2005.

THIOLLENT, Michel. Notas para o debate sobre a pesquisa-ação. Serviço Social \& Sociedade, São Paulo, ano 4, n. 10, p. 123-141, dez. 1982.

THIOLLENT, Michel. Metodologia da pesquisa-ação. São Paulo: Cortez, 1994.

TRILLA, Jaume. La educación fuera de la escuela: ámbitos no formales y educación social. Barcelona: Ariel, 1996. 